\title{
EVOLUÇÃO DA TEORIA DA "UNIVERSITAS"
}

\author{
Ernani Guarita Cartaxo \\ Professor da Faculdade de Direito \\ da Universidade do Paraná.
}

\begin{abstract}
O conceito teórico da pessoa jurídica não podia deixar de ser estranho ao direito rudimentar das primeiras épocas de Roma. O realismo das suas fórmulas não ia além da compreensão dos fatos, segundo a expressão concreta das suas aparências. Não alcançava as generalizações, e não podia, pois, perceber o conceito jurídico-filosófico da personalidade subjetiva, que veio a se aplicar aos organismos sociais, por um processo de generalização.
\end{abstract}

A pessoa jurídica, em suas modalidades de corporação, estabelecimento e fundação, como sujeito de direitos distinto e independente dos indivíduos, que o compõem, assinala Von Mayr, (1) é um mecanismo técnico alheio às concepções simplistas da época antiga. A idéia de que o que pertence à coletividade não pertence a cada um dos seus membros, supõe uma capacidade de abstração, incompatível com as noções rudimentares da era inicial de Roma.

Evidentemente, ao antigo direito romano era indiferente a conceituação da pessoa jurídica, dada a predominância das

1) VON MAYR, “História del Derecho Romano", 1926. II, p. 168. 
formas puramente realistas e exteriores dos fatos, na construção das regras jurídicas.

"As leis e as idéias de uma época bárbara, diz Von Ihering, exigem homens, que lhes sejam contemporâneos, seres incultos e grosseiros, que não tenham senão o conhecimento daquilo, que possam alcançar com a mão. Palpaveis, exteriores e sensíveis, tais são as noções do direito antigo. Nele, a forma exterior predomina sôbre a idéia. Os resultados imediatos e os objetos perceptíveis são os únicos, que se levam em conta". (2)

Aludindo particularmente às pessoas jurídicas, anota o grande romanista: "Esta é uma abstração, que a inteligência não pode conceber sem um certo grau de desenvolvimento, e que não podemos, em consequência, atribuir à época da infância do direito".

Cuq assinala, de sua parte, que a noção abstrata da pessoa jurídica era alheia ao antigo direito romano, (4) e na generalidade dêsse conceito insiste Barcia López, sob a razão de que, em parte, a primitiva inadmissibilidade da representação, idéia a que o direito romano se mostrou por largo tempo rebelde, devia ser também um obstáculo à introdução de uma teoria, que a reclamava, como seu postulado essencial. (5)

Certo é, entretanto, que a constatação da inexistência da subjetividade dos órgãos associativos, nos primórdios do direito romano, não resulta senão da aplicação de um processo de análise, que objetiva encontrar nos tipos coletivos dessa época os característicos que, mais tarde, vieram configurar o fenômeno jurídico da personalidade subjetiva, na conformidade das creações teóricas, que se levantaram em face da própria existência dêsses entes de direito.

Há, assim, nessa apreciação, uma relatividade, que não deve passar desapercebida. Os fatos dão origem às generaliza-

2) VON IHERING, "El espiritu del Derecho Romano", 1912, III p. 128.

3) Op. cit., I, ob. 147, p. 236.

4) EDOUARD CUQ, "Institutions Juridiques des Romains", 1917, p. 114.

5) BARCIA LOPEZ, "Las Personas Juridicas", 1922, p. 8. 
ções de caráter teórico. Estas, depois, é que vão servir de medida, para a apreciação retrospectiva dos próprios fatos, Há assim uma reciprocidade de efeitos, que tende a desnaturar 0 conceito do fato originário em favor da concepção doutrinária, que se formou por um processo de sistematização teórica. (6)

Em direito, ensina Saleilles, (7) são as necessidades sociais, que fazem surgir as instituições: estas se geram e desenvolvem em vista dos resultados práticos, que delas se esperam, sem que se cogite, neste ponto inicial, de consultar a teoria da sua legitimidade e da sua justificação. Só muito mais tarde, quando se quer estender ou restringir os efeitos de uma instituição jurídica, é que se procura conhecer a sua natureza fundamental e o seu caráter racional, exatamente para deduzir-se desta construção abstrata um motivo de extensão ou restrição, segundo um particular ponto de vista. E quasi sempre a construção, ela mesma, é dominada, insensivelmente, pelo objetivo primordial, que inspirou a própria pesquisa, tal êsse ou aquele resultado, a deduzir-se de um princípio. Vê-se primeiro o resultado, procura-se depois o princípio: é essa a gênesis de tôda a construção jurídica. Uma vez aceita, ela se apresenta, por isso mesmo, sob um aspecto oposto, no complexo das conclusões

6) Ao lado da relatividade da justaposição do tipo associativo à matriz teórica da pessoa jurídica, que lhe deve corresponder, pode-se também acentuar a relatividade do próprio conceito literal da persona "omne jus, quo utimur, ad personas pertinet..." GAIO, I, 8), para entende-la como alusiva não só ao homem capaz de direitos, mas ao próprio escravo (GAIO, I, 9; I. 49; POMPONIO, D. 12 (18,1); PAULO, D. $215(50,16)$; ULPIANO, D. $22(50,17)$, quando é sabido que os escravos não são considerados pessoas, pro nullo habentur (ULPIANO, D. $1(28,8)$. Daí a conclusão esposada por PEROZZI ("Instituzioni di Diritto Romano", 1906, p. 127) de que, entre os escritores da idade da jurisprudência clássica, apenas os gramáticos usam o termo persona (“ persona coloniae", "persona publica") para significar um ente coletivo à semelhança do homem, não como ser capaz de direitos, mas como ser físico, na sua expressão de ente vivo. Para o escritor, o germe do conceito moderno da pessoa se encontra nas fontes post-clássicas, nas quais o termo persona é usado para indicar a capacidade de um dado direito, como a de estar em juizo - Cód. $(3,6)$ rúbrica: "Qui legitiman personam standi in judiciis habeant, vel non", - ou uma capacidade geral. Assim, somente nas fontes bizantinas, persona assume, ao lado do antigo significado genérico de "homem", aquele de "homem capaz de direitos".

7) SALEILles, “De la Personnalité Juridique”, 1922, III leçon, p. 45. 
dogmáticas. A construção aparece aí como a causa inicial, de onde decorre o resultado, que se procurava.

Assim, quando se afirma que as condições teóricas da subjetividade das pessoas jurídicas não são encontradas nos corpos coletivos das primeiras épocas de Roma, ou em certas corporações de épocas posteriores, estabelece-se um conceito puramente relativo, e essa relatividade decorre, já da singularidade de certas instituições, que não encontram correspondência em tipos congêneres de épocas posteriores, já da peculiaridade de determinados corpos associativos, que, agindo num meio radicalmente diverso, apresentam, de sua vez, caracteres, que lhes são particularmente típicos.

Nesse plano de conceituação relativa, inclue-se o Estado romano, (8) a cuja subjetividade devemos aludir, desde logo. Essa entretanto, embora se exercite no domínio do direito privado, não deriva de um fracionamento da sua personalidade, ao diverso do fenômeno, que ocorre nas pessoas de direito público modernas, enquanto agem em idênticas condições. 0 populus romanus é sempre soberano, e a sua atividade é constantemente regulada pelo jus publicum, ainda quando entra, no plano patrimonial, em contacto com os particulares. Essas relações, embora o Estado as exerça nos moldes dos negócios privados, nesse aspecto regidos pelas regras do jus singulorum, ostentam 0 caráter de atividade pública, e sobretudo um teor evidentemente legal, distanciado dos efeitos comuns, que as normas contratuais poderiam ordinàriamente produzir. Exemplifica essa conceituação a natureza da conductio, que o Estado estabelece com os publicani, (9) ou sejam os fornecedores dos exércitos, em-

8) MISPOULET assinala que a idéia de Estado, no sentido moderno do termo, era desconhecida dos romanos, mercê da sua constituição comunal. Esta concepção da cidade antiga não se altera até o fim da República. Modificam-se um pouco no período do Império, mas em nenhuma época aparece claramente a idéia de Estado ("Institutions Politiques des Romains", 1883, II, § 83).

9) No sentido estrito, publicano é aquele que se obriga, perante o Estado, a pagar-lhe anualmente uma soma cieterminada, a título do imposto, cuja percepção lhe foi enireşue: "publicani autem dicuntur, "qui publica vectigalia habent conducta". ULPIANO, D. 12 § $3 \ldots$. $(39,4)$. 
preiteiros de trabalhos públicos e locadores de impostos, com os quais estipula relações obrigacionais, que, pela extensão dos seus efeitos, traem, na pessoa do contratante, a entidade de direito público, que melhor legisla, que contrata.

Assim, aos publicanos competia o direito de penhor contra os devedores do imposto, com fundamento numa lei censória: lege censoria data est pignoris capio publicanis vectigalium publicorum populi romani adversus eos, qui aliqua lege vectigalia deberent. (10) Ora, si se tratasse de um contrato de natureza privada, dêle não poderia decorrer, em favor de um dos contratantes, o direito de execução contra terceiros, estranhos ao contrato, ou seja contra os devedores dos impostos. De sua vez, a transferência direta do crédito, relativo ao imposto, do Estado para os pub̆licani, transferência contrária ao princípio da incedibilidade das obrigações, evidencia um efeito, que ultrapassa o alcance da vontade de contratantes comuns, submetidos às regras ordinárias do jus privatum. É que o Estado, ao contratar com os patriculares, não se despia inteiramente da sua condição de poder soberano, para se apresentar como uma pessoa jurídica privada, no mesmo plano comum dos cidadãos.

Sob nenhum aspecto, o Estado se subordina a qualquer alçada judiciária, para apreciação e decisão dos seus direitos litigiosos, e assim não se submete à autoridade judiciária, ou às formas ordinárias do processo. A defesa dos seus interêsses é regulada administrativamente pelo censor, ainda que respeitasse à execução de normas contratuais. Fundado nessa observação, Savigny anota que não é como decorrência do Estado, ou da sua condição de titular de bens, que se estabelece ou desenvolve o princípio jurídico da pessoa de direito, desde que a defesa dos seus interêsses era tutelada por normas especiais e garantias específicas, das quais é exemplo o jus praediatorium. (11)

No plano patrimonial, vemos entretanto a incontestável soberania do Estado revestir-se de uma certa capacidade priva-

10) GAIO, IV, 28.

11) SAVIGNY, "Traité de Droit Romain", II § 87. 
da, que, certo, não chega a obliterar a noção de poder público, que lhe é precípua, mas serve para tornar mais complexa a sua conceituação. Os bens do Estado são res publicae, e nessas condições nullius videntur in bonis esse, ipsius enim universitatis esse creduntur. (12) Mas, sem dúvida, ao lado das verdadeiras cousas públicas, ou mesmo comuns, ou ainda pertencentes às cidades, aer, aqua profluens, mare, litora, flumina, portus, theatra, stadia, etc. (13) existem, no patrimônio do Estado, certos bens, que fazem lembrar um domínio privado, ao lado do seu domínio público, por excelência, integrado por bens evidentemente extra commercium. Estão nessa compreensão o ager publicus, o ager compascuus, os agri limitati, os servi publici, e ainda as cousas que, eventualmente, se tornam propriedade do Estado, porque tomadas ex hostibus, sendo pois consideradas publicae (14) e assim vendidas pelos questores, emptio sub corona. Sôbre tais bens, o Estado não exercerá exclusivamente o seu direito de soberania, mas, de qualquer forma, um certo direito de propriedade privado. (15)

Ferrini ensina que é o Estado romano a principal e mais antiga pessoa jurídica, sôbre cujo tipo tôdas as outras em seguida se formaram, e parcialmente concorda Ferrara com o asserto, no sentido em que os entes coletivos se apresentam modelados sôbre o Estado, mas adverte que o aspecto essencial da questão é saber-se quando êstes entes publicísticos se tornaram pessoas jurídicas, isto é, sujeitos de relações iguais às pessoas físicas, e ao lado destas. (16)

12) GAIO, II, 11.

13) I. de rerum divisione $(2,1)$.

14) Pela lex Julia peculatus pune-se a apropriação "ex pecunia sacra, "religiosa publicave", e assim o roubo da cousa tomada ao inimigo, conforme o texto de MODESTINO: "Is qui praedam ab hostibus cap"tam subripuit, lege peculatus tenetur, et in quadruplum damnatur". D. $13(48,13)$.

15) Observa GIRARD que a propriedade do Estado sôbre as res publicae resulta sobretudo da circunstância de ser êle normalmente proprietário da maior parte delas, antes de fazê-las passar do seu domínio privado para o domínio público, ao entregá-las ao uso comum. $\mathrm{E}$, ainda depois desta destinação, decorre igualmente do fato de continuar a retirar delas as vantagens compatíveis com o direito de propriedade, do que é exemplo o solarium; pago a título de ocupação do solo ("Droit Romain", 1928, III, p. 247).

16) FERRARA, “Teoria delle Persone Giuridiche", 1923, cap. I, § 1. 
Anote-se que a pessoa jurídica surge primeiramente no direito público, antes de penetrar o direito privado. E, como assinala Cuq, (17) é no direito público, e em relação ao mais importante de todos os grupos, ou seja, o povo romano, que surge inicialmente a necessidade de distinguí-lo dos indivíduos, que o compõem. Há uma época em que o Estado se confunde com a massa dos cidadãos, (18) mas essa indeterminação tem limites, e os encargos e as responsabilidades públicas e particulares acabam se distinguindo. (19) Só então, já nas épocas do Principado, começam a ser nítidos os traços delineativos da pessoa jurídica, que há nos corpos públicos, ou de direito público, tais o Estado, os municípios, as colônias e as cidades, para o que igualmente concorrem as condições peculiares das comunas conquistadas, em solo itálico, a que Roma permite a sobrevivência dos seus direitos gerais, depois de lhes retirar a autonomia política. Até êste tempo, o regime de indistinção, que envolve o Estado e os cidadãos, envolve, de sua vez, as organizações associativas, que congregam coletivamente interêsses privados, e se mantém sob a tutela do poder público. Nelas, dessa forma, não se percebe a personalidade jurídica, ou, apenas se percebem os elementos embrionários dessa personalidade, mercê da sua filiação ao poder público, de que, na sua expressão civil ou religiosa, são antes accessórios, que entidades autônomas. As corporações de sacerdotes, dedicadas ao culto dos deuses públicos, já numerosas no antigo direito, incluem-se nessa categoria, e devem ser tidas como entidades de caráter público, atenta a intimidade do nexo existente entre a religião

17) CUQ, op. cit., p. 115.

18) São exemplos dessa confusão o direito de ocupação do ager publicus, o conceito de serem as res communes patrimônio do povo, o exercício das ações populares, "ubi quis, quasi unus, ex populo agit".

19) ULPIANO: "Civitas mutui datione obrigari potest, si ad utilitatem "ejus pecuniae versae sunt: alioquin ipsi soli qui contraxerunt, non "civitas, tenebuntur". D. 27 (12,1). PAULO: "Caius Seius, qui rem "publicam gerebat, foeneravit pecuniam publicam sub usuris solitis... "Quidam debitores cessaverunt in solvendis usuris; quidam plus in"tulerunt... Quaesitum est an illud quod amplius ex consuetudine a "quibusdam exactum est, ipsi Seio proficere deberet, an reipublicae "lucro cederet? Respondi... eas (usuras) solas reipublicae praestari "oportere, quae secundum formam ab his exigi solent..." D. 11 $(22,1)$. 
e o poder civil romanos. Na verdade, a organização religiosa dos romanos não era distinta da organização pública. É, como esta, obra do legislador. (20) Os sacerdotes não tinham o privilégio exclusivo da celebração dos atos religiosos. Os magistrados podiam, de sua parte, celebrá-los. A religião confundia-se com todos os atos importantes da vida pública ou privada. (21)

Assim, os antigos colégios sacros, os colégios dos pontífices, os colégios em geral dos sacerdotes ou sacerdotisas têm apenas uma personalidade reflexa, pois os seus bens provem geralmente de uma concessão do Estado, que lhes permite a sua utilização, e participam do ager publicus, considerando-se, de sua vez, os escravos do templo como servi publici, ainda que possam os colégios ter bens por outro título. (22) 0 patrimônio, ou família, atribuido aos deuses, (23) e que de fato parecem lhes pertencer, melhor se consideram adquiridos pelo Estado, em face da organização político-religiosa de Roma, e assim apenas permanecem a serviço da religião.

Sem dúvida, mais definida é a personalidade das sodalitates, ou colégios religiosos privados, destinados ao culto dos deuses estrangeiros ou das divindades particulares, e que, ao lado

20) A Lex Coloniae Genetivae Juliae, ou seja o estatuto municipal dessa colônia de cidadãos romanos, regula, minuciosamente, nos capítulos 64 a 73, tudo quanto respeita ao culto religioso: a organização dos sacerdócios, as despesas do culto, a celebração dos ritos e o estabelecimento dos dies fasti (GIRARD, "Textes", p. 89).

21) VON IHERING, op. cit., I, § 21.

22) SCAEVOLA: "Fideicommisit ejus cui duo millia legavit, in haes ver"ba: A te, Petroni, peto uti ea duo millia solidorum reddas collegio "cujusdam templi". D. 38 \& 6 (32, III). HYGINUS: "Virginum quo"que vestalium et sacerdotum quidam agri vectigalibus redditi sunt "et locati". ("De conditione agrorum", ed. Goesii, p. 206).

23) CICERO: "Martiales quidam Larini appellabantur, ministri publice "Martis, atque ei deo veteribus institutis religionibusque Larinatium "consecrati: quorum quum satis magnus numerus esset, quumque "item, ut in Siciliâ permulti Venerei sunt, sic illi Larini in Martis fa"milia numerarentur, repente Oppiniacus eos omnes liberos esse ci"vesque romanos coepit defendere". Pro A. Cluentio (XV). Idem: "Agonis est quaedam, Lilybaetana, liberta Veneris Erycinae; quae "mulier ante hunc quaestorem, copiosa planè et locuples fuit. Ab hac "praefectus Antonii, quidam symphoniacos servos abducebat per in"juriam, quibus se in classe uti velle dicebat. Tum illa, ut mos in Si"ciliâ est omnium Venereorum, et eorum, qui à Venere se liberave"runt, ut praefecto illi religionem Veneris nomenque objiceret, dixit "et se et omnia sua, Veneris ese. "In Q. Caecilio (XVII). 
dos seus fins próprios, relativos ao exercício em comum das solenidades rituais, tinham igualmente o objetivo accessório de prover os funerais dos associados pobres, e mesmo escravos. (24) Os colégios funerários, em face dessa circunstância, são designados, nos textos da época clássica, sob a denominação de colleǵia tenuiorum. (25) A êles devem juntar-se os colégios destinados ao culto oficial, como o colégio dos tibicines. (26)

Enquanto êstes apresentam um caráter nìtidamente relacionado com objetivos religiosos, já as corporações profissionais do direito antigo, como as de artífices, corpora fabrorum, cujos trabalhos se reputam de necessidade pública, (27) aparecem de certa forma identificados com as atividades da comunidade municipal, e têm, como os colégios religiosos, um fim igualmente funerário, em relação aos seus membros. (28)

À constatação da natureza das coletividades do direito antigo, conclue Gierke que elas não constituem senão partes derivadas do único sujeito de todos os direitos públicos, o Estado, pelo que não era de se lhes emprestar qualquer conceituação específica de personalidade, considerada a sua subordinação, ou

24) Exemplo dessas associações é o colégio funerário de Lanuvium, "Col"legium cultorum Dianae et Antinoi", cujos estatutos constam de uma inscrição descoberta em Levigna, em 1816 (GIRARD, “Textes", p. 888).

25) MARCIANO: "Sed permittitur tenuioribus stipem menstruam con"ferre, dum tamem semel in mense coeant." "Servos quoque licet in "collegio tenuiorum recipi volentibus dominis". D. 1 ; $3 \S 2(47,22)$.

26) Segundo Mommsen, com o colégio dos tibicines confunde-se o colégio dos symphoniaci, de músicos religiosos, do qual existe a seguinte inscrição: "Dis manibus: collegio symphoniacorum, qui sacris publi"cis praestu sunt, quibus senatus coire convocari cogi permisit et le"ge Julia ex auctoritate Augusti ludorum causa". (GIRARD, "Textes", p. 887).

27) CALLISTRATO - "Quibusdam collegiis vel corporibus quibus jus coeundi lege permissum est, immunitas tribuitur: scilicet eis collegiis vel corporibus, in quibus artificit sui causa unusquisque adsumitur: ut fabrorum corpus est, et si qua eandem rationem originis habent, id est, idcirco instituta sunt ut necessariam operam publicis utilitatitus exhiberent". D. 5 § $12(50,6)$.

28). GEORGE CORNIL, "Droit Romain", 1921, p. 162. 
ao menos a sua correlação com a administração política ou religiosa do Estado romano. (29)

O conceito de pessoa jurídica entra a ganhar traços caraterísticos, e se desenvolve ao tempo do Império, como decorrência da constituição dos municípios e cidades dependentes de Roma.

Ao estenderem os romanos a sua dominação sôbre tôda a Itália, as antigas cidades, submetidas pela conquista, são anexadas ao Estado romano, que lhes outorga uma constituição municipal e uma relativa autonomia. Mas Roma, ao lhes anular a sua existência política, em razão da sua incorporação ao Estado, deixa-lhes uma incontestável capacidade privada, que lhes permite participar das relações comuns do direito privado. Despojados da sua antiga soberania, e tornados membros distintos de uma outra entidade pública, os municipia, por exigência da sua condição de corpos políticos desprovidos de soberania, se viram submetidos às regras do jus singulorum, forçados a usar as formas ordinárias do direito privado e, ainda, a figurar em juizo, conforme as regras do procedimento civil. Assumem, nas relações jurídicas privadas, a posição das pessoas físicas. Da excepcionalidade da sua condição nascem a idéia e o conceito

29) SAVIGNY, anteriormente, iá havia assentado idênticos conceitos. Encontramos entre os romanos, diz êle, desde os primeiros tempos da sua história, associações permanentes de várias espécies, confrárias de sacerdotes e artífices, como associações de funeionários subalternos. Entretanto, a necessidade de constituir a pessoa jurídica pouco se fazia sentir, de vez que, para essas diversas associações, o objeto mais importante era a comunidade de ação e, também, a posição política. A capacidade de propriedade não oferecia senão um interêsse secundário. 0 culto dos deuses acarretava grandes despesas, mas estas estavam a cargo do Estado, o que tornava desnecessária qualquer destinação de bens, seja em favor dos colégios, seja em favor dos templos. Si se entendia constituir uma fundação para o culto, bastante era a consagração dos bens, que compunham a doação. 仓̂les tornavam-se desde logo fora do comércio, sem se tornarem propriedade, quer do templo, quer dos sacerdotes (op. cit., II, § 87). 
originais da pessoa jurídica, que a especulação generalizadora dos juristas aperfeiçoa. (30)

Quando o Estado romano se expande, diz Savigny, foi pelas comunas colocadas sob a sua dependência, os municípios e as colônias, que a idéia da pessoa jurídica passa a ter aplicações importantes, e se desenha nitidamente. Na verdade, elas tinham, como as pessoas naturais, a necessidade de possuir e os meios de adquirir, e a sua condição de dependência as sujeitava à jurisdição dos tribunais. (31)

Vauthier, de sua vez, reafirma a procedência da opinião, que relaciona a noção da pessoa jurídica com a condição peculiar das cidades itálicas conquistadas, ao considerar que elas passam da ordem do direito público para a ordem do direito privado, desde que o Império as despoja das suas funções propriamente políticas e as obriga a se acantonar na esfera dos interêsses privados. Não que, até então, tôda a relação de direito privado lhes fôsse desconhecida, mas o certo é que estas relações não tinham ainda sido estudadas e sistematizadas. Uma vez que a cidade foi quasi inteiramente reduzida à condição de associação privada, ela deixa de parecer refratária ao império das regras ordinárias do direito. Trata-se assim de estender a um grupo extremamente numeroso de comunidades os princípios, que regiam a existência e os atos de um particular (32)

É de se observar que a capacidade jurídica dos municípios inter vivos se equiparava a das pessoas físicas. Causa mortis, podiam adquirir legados, compreendidos os fideicomissos a tí-

30) Ao lado do município de Roma, assinala, VON MAYR, gozavam de personalidade jurídica os municípios associados, dentro do Estado romano. Com a diferença de que a capacidade jurídica dos municípios variava segundo a sua posição em face da organização romana, e se aproximava mais da pessoa de direito privado que da do populus romanus. As civitates, que ao se incorporarem a Roma haviam conservado a sua independência, eram pessoas jurídicas independentes. $\mathbf{E}$ também eram assim tratadas as cidades submetidas, mas estas sofriam restrições em sua personalidade, por motivo da soberania do povo romano. As colônias careciam de personalidade. A época imperial desapareceram estas diferenças, e todos os municípios obtem a consideração de sujeitos independentes de direito (op. cit., II, p. 38).

31) SAVIGNY, op. cit., II, $\S 87$.

32) VAUTHIER, "Edudes sur les Persones Morales", 1887, p. 18. 
tulo particular, (33) e mais tarde receber fideicomissos universais. (34) Estiveram entretanto privados de suceder hereditariamente por testamento, durante tôda a época clássica, salvo quanto aos bens dos seus libertos. (35) Para a realização dos negócios jurídicos, que interessassem ao seu patrimônio público, tais as locações de impostos e vendas de bens, a sua representação estava a cargo dos seus órgãos oficiais, segundo as regras do direito público. Nos outros casos, representavam o município os actores nomeados para êsse fim, na conformidade dos princípios do direito privado. Êsses podiam ser citados em juizo, por parte do liberto da cidade. (36)

O sistema, que emprestava personalidade jurídica ao município, devia difundir-se sem demora, e passou a aplicarese a outros corpos de natureza jurídica, submetidos ao jus privatum. Elabora-se dessa forma uma nova concepção, que entra a caraterizar as demais coletividades como sujeitos de direito, ou seja como pessoas jurídicas, revestidas de capacidade privada, à semelhança dos municipia, ou da respublica. Daí o novo conceito jurídico, que se vem a atribuir a todos os tipos associativos do direito coletivo de Roma: sodalitates, collegia, corpora, populus.

Dí-lo expressamente Gaio: Quibus autem permissum est corpus habere collegii, societatis, sive cujusque alterius eorum nomine, proprium est, ad exemplum reipublicae, habere res communes, arcam communem, et actorem .vel syndicum, per

33) ULPIANO: "Civitatibus omnibus, que sub imperio populi romani "sunt, legari potest; idque a divo Nerva introductum, postea a se"natu auctore Hadriano diligentius constitutum est". ("Regulae" XXIV, 28).

34) PAULO; D. $26(36,1)$.

35) ULPIANO: “Nec municipia, nec municipes heredes institui possunt, "quoniam incertum corpus est, et neque cernere universi neque pro "herede gerere posunt, ut heredes fiant: senatus-consulto tamen con"cessum est ut a libertis suis heredes institui possint". ("Regulae", XXII, 5).

36) ULPIANO: "Qui manumittitur a corpore aliquo, vel collegio, vel ci"vitate... si adversus rempublicam vel universitatem velit experiri, "veniam edicti petere debet, quanvis actorem eorum constitutum in "jus sit vocaturus". D. $10 \S 4(2,4)$. 
quem, tanquam in republica, quod communiter agi fierique oporteat, agatur, fiat. (37)

Na verdade, ensina Savigny, uma vez estabelecida definitivamente para as cidades dependentes, a instituição da pessoa jurídica se estende pouco a pouco a casos, nos quais dificilmente se teria pensado em aplicá-la. Assim se aplica às antigas confrarias de sacerdotes e artífices; em seguida, por via de abstração, ao Estado, que, sob o nome de Fisco, foi tratado como uma pessoa, e submetido a uma jurisdição; enfim, a sujeitos de uma natureza puramente ideal, como os deuses e os templos. (38)

Como observa Ferrara, (39) citando Liebenam e Pernice, e bem assim Saleilles, (40) a analogia entre os municipia e os colegia descia às menores particularidades. Os colégios, à maneira das comunas, se colocam sob a invocação da divindade, têm um estatuto próprio, lex collegii, correspondente à lex $m u$ nicipalis, chamam curia ao seu local de reunião, têm o seu defensor, ou actor, cometem a sua gestão a administradores, que são verdadeiros magistrados, e usam os mesmos títulos dos funcionários municipais, como magister, curator, duumviri, quaestor, tribunus, aedilis.

Paralelamente à capacidade patrimonial do município, foi se desenvolvendo a capacidade dos colégios, mercê de um fenômeno reciprocamente reflexo, caraterizado, em geral, pelas hesitações e incertezas, decorrentes tanto do desenvolvimnto gradativo da personalidade dos municipia, como dos privilégios concedidos ou negados às universitates, conforme testemunham as controvérsias dos jurisconultos. Sujeito de direito, na esfera das relações sucessórias, como vimos, o município era servido de uma capacidade mais ou menos ampla, na conformidade dos casos. Como, entretanto, se duvidava anteriormente si lhe era permitida a aquisição da posse, duvidava-se igualmente si esta

37) D. $1 \S 1(3,4)$.

38) SAVIGNY, op. cit., $\S 87$.

39) FERRARA, op. cit., cap. $1, \S 1$.

40) SALELLIES, op. cit., IV leçon, p. 75. 
podia competir às pessoas jurídicas, em geral. (41) Afinal veio a considerar-se que, como a cidade, as corporações podiam analogamente adquirir a posse. (42)

Ao município, a que devia faltar a capacidade ordinária de praticar atos de simples liberalidade, foi outorgada afinal, por uma lex Vectibulici, sob o principado de Adriano, a faculdade de libertar os seus escravos, faculdade essa estendida após às províncias da Itália, por um senatus-consulto, promulgado ainda no reinado de Adriano. (43) Do mesmo passo, concedia-se às comunas, como um acessório lógicơ, os jura patronatus sôbre os seus libertos. (44) Pela assemelhação resultante da sua indentidade jurídica, êsse direito não podia deixar de ser concedido aos collegia, e assim é que Marco Aurélio vem a permitir-lhes manumitir, da mesma forma, os seus escravos. (45)

Vimos que o município era capaz de receber legados e incapaz, em regra, de suceder por testamento. Da mesma forma, o colégio, legalmente autorizado, tinha capacidade para ser le-

41) PAULO: "Municipes per se nihil possidere possunt, quia universi "consentire non possunt. Forum autem et basilicam hisque similia "non possident, sed promiscue his utuntur. Sed Nerva filius ait, per "servum, que peculiariter adquisierint, et possidere, et usucapere pos"se; sed quidam contra putant, quoniam ipsos servos non possident". D. 1 \& $22(41,2)$.

42) ULPIANO: "Sed hoc jure utimur, ut et possidere et usucapere muni"cipes possuint, idque iis et per servos et per liberam personam adqui"ratur." D. 2. (41,2). Do mesmo: "Item municipes ad exhibendum "conveniri possunt, quia facultas est restituendi; nam et possidere "et usucapere eos posse constat; idem et in collegiis caeterisque cor"poribus dicendum erit". D. 7 § $3(10,4)$.

43) Impp. DIOCLECIANO e MAXIMIANO: "Si itaque (manicipum liber“tus) secundum legem Vectibulici (cujus legis potestatem senatus"consulto Jubentio Celso iterum et Neratio Marcello consulibus fac"to, ad provincias porrectam constitit) manumissus, civitatem roma"nam consecutus es..." C. $3(7,9)$.

44) ULPIANO: "Municipibus plenum jus in bonis libertorum, liberta"rum defurtur, hoc est, id jus quod etiam partono". D. pr. $(38,3)$.

45) ULPIANO: "Divus Marcus omnibus collegiis, quibus coeundi jus est, "manumittendi potestatem dedit." D. $1(40,3)$. 
gatário, (46) mas não podia, por direito comum, ser instituido herdeiro. (47)

Quanto à bonorum possessio, as corporações, em geral, ainda se assemelham ao município. De início, duvidava-se da capacidade dêste para adquirí-las: sed an omnino petere bonorum possessionem possunt (municipes), dubitatur. (48) Quando, entretanto, esta faculdade lhe é reconhecida, permitindo-se-lhe per alium petita bonorum possessione adquirere, a mesma faculdade é atribuida, em geral, às demais pessoas jurídicas. (49)

Mas as analogias entre o município e o colégio, decorrentes da estruturação jurídica, a que êste foi submetido, segundo o modêlo daquele, admitem a intervenção paralela de outros fatores, que, no terreno legal ou no plano histórico, contribuiram igualmente para essa assemelhação.

De um lado, o regime de autorização prévia do poder público, creado pela lex Julia de collegiis, para a constituição das associações, integrou-as, oficialmente, entre os organismos do Estado, e estabeleceu, entre aquelas e êste, uma relação de equiparação, ou de filiação. De outra parte, tôdas as comunidades romanas, desde os mais recuados tempos, obedeceram sempre a um critério uniforme de organização, moldada esta no mesmo tipo associativo, que era o único, no conceito romano. Daí a indeterminação entre a esfera de atividade pública e a de atividade comum, no terreno das construções corporativas, e em consequência a forma administrativa, a que se subordinam

46) PAULO: "Cum senatus temporibus divi Marci permiserit collegiis le"gare, nulla dubitatio est, auod si corpori, cui licet coire, legatum "sit, debeatur. Cui autem non licet, si legatur, non valebit, nisi sin"gulis legetur: hi enim, nom quasi collegium, sed quasi certi homines "admittentur ad legatum". D. 20 (34,5).

47) Impp. DIOCLECIANO e MAXIMIANO: "Collegium, si nullo speciali "privilegio subnixum sit, hereditatem capere non posse, dubium non "est". C. $8(6,24)$.

48) ULPIANO, D. 1 \& $1(38,3)$.

49) ULPIANO: “A municipibus, et societatibus, et decuriis, et corporibus "bonorum possessio adgnosei possunt. Proinde, sive actor eorum no"mine admittat, sive quis alius, recte competet bonorum possessio". D. $3 \S 4(37,1)$. 
em geral as associações, e do que lhes resulta um sentido de aparente identidade. (50) No molde da própria civitas, que não é outra cousa senão um colégio, mais amplo que os outros, mas da mesma natureza, estruturam-se tôdas as corporações, que agrupam os homens pelos seus ofícios, os sacerdotes pelas suas funções, os interessados nos serviços públicos pela natureza dos seus encargo, conforme êstes se relacionem com a administração financeira, com a organização anorária ou com as atividades industriais do Estado.

Nesse aspecto, todos os grupos corportivos entrosam-se, de uma ou de outra forma, na máquina administrativa da cidade, e são elementos necessários do organismo público, num grau de subordinação, que corre paralelo à gradativa evolução do poder político para a centralização e o despotismo. (51)

A intervenção da lex Julia de collegiis é que melhor delínea, entretanto, na esfera jurídica, a identidade dêsses corpos publicísticos, como os apelida Ferrara, (52) com a unidade comunal, que é o seu tipo. De visto, a participação da autoridade pública na constituição dos colégios oficializa ostensivamente a sua existência, e, reforçando uma : afinidade de funções já existente, integra-os, agora legalmente, na esfera de atividade acentuadamente pública, de que já participavam, no regime da liberdade de associação.

Neste aspecto, a lex Julia de collegiis, constitue, sem dúvida, um marco divisório na história do direito corporativo de Roma. Desde os começos da República, as associações se formavam livremente, sem dependêndia de uma autorização prévia do Senado. Prevalece o regime da liberdade associativa. de se distinguir, entretanto, que o livre direito de associação não isentava o grupo corporativo da vigilância do poder público, e pois não significava ilimitada liberdade estatutária, con-

50) SALEILLES desenvolve, com notável erudição, na quarta lição do seu magnífico curso, êste aspecto do direito associativo de Roma, (op. cit., p. 68).

51) Confere: WALTZING, "Edude historique sur les corporations professionnelles chez les Romains", 1896, II, p. 255.

52) FERRARA, op. cit., cap. I § $10^{\circ}$. 
dições aliás que não se confundem. A liberdade de associação respeita ao direito de livre existência do órgão associativo, e se opõe ao regime de autorização prévia do Estado, como condição preliminar de existência. A atividade social, derivante da lex collegii e condizente com os interêsses finalísticos do grupo, êsse, já agora, pode sofrer restrições, desde que, por motivo de natureza política, moral ou razão diversa, contrarie a ordem legal ou o interêsse público, seja pelo caráter das normas estatutárias, seja pela desvirtuação do sentido coletivista inicial. Essa ação repressiva não contradiz entretanto, pela sua incidência a posteriori, o princípio da liberdade associativa, que a lei das XII Táboas expõe literalmente, ao referir-se ao direito concedido aos colégios de se organizarem segundo os estatutos, que entendam pactuar: Sodalibus LEX facit potestatem sibi ferre pactionem quam velint, dum ne quid ex publica lege corrumpant. (53)

A sombra dêsse regime, fundam-se e difundem-se em Roma, desde entã́o, em avultado número, pequenos colégios de artífices, ou não, que visavam a mútua assistência dos seus membros, a celebração de solenidades religiosas, e especialmente os encargos dos seus funerais.

Pela primeira vez, já ao fim da República, no consulado de Cícero, o Senado utiliza, em caráter geral, os seus poderes de fiscalização, e por um ato de natureza política, suprime tôdas essas associações, que se haviam tornado perigosa à tranquilidade do Estado. (54) Deixa entretanto subsistirem as an-

53) GAIO: "Sodales sunt, qui ejusdem collegii sunt. His autem potesta"tem facit lex pactionem auam velint sibi ferre, dum ne quid ex pu"blicae lege corrumpant. Sed haec lex videtur ex lege Solonis trans"lata esse, nam illic ita est: si autem plebs, vel fratres, vel sacrorum "sacramentales, vel nautae, vel confrumentales, vel qui in eodem se"pulcro sepeliuntur, vel sodales, qui et multum simul habitantes sunt, "enimvero ad negotiationem aut quid aliud: quidquid hi disponent ad "invicem firmum sit, nisi hoc publicae leges prohibuerint." D. 4 $(47,22)$.

54) O episódio relaciona-se com a conjuração de Catilina, a cujos intuitos políticos essas associacões passaram a servir, tornando-se, em consequência, centros de agitacão sediciosa. 0 senatusconsulto, que as extinguiu, data do ano de 64 , antes da era cristã (GILLET, "La personnalité Juridique en Droit Ecclesiastique", 1927, p. 10). 
tiquíssimas corporações de artífices, que faziam parte das instituições administrativas da cidade, e cuja fundação a lenda atribue aos primeiros reis de Roma.

Mas a proibição não era destinada a perdurar, tanto mais quanto as associações suprimidas participavam da vida popular, cumprindo-lhes a celebração de festas públicas. Assim é que o tribuno Publius Clodius consegue em seguida restabelecer os colégios dissolvidos, fazendo votar uma lei, nesse sentido. (55)

Cesar, ao assumir o poder, quando então as associações restabelecidas se constituiam novamente em focos de agitações partidárias, suprime-as, de novo, sem que entretanto a medida atinja as corporações, já respeitadas, anteriormente. (56)

Ao regime de dissoluções esporádicas dos colégios devia suceder uma orientação de caráter permanente, norteada no sentido de sujeitar a constituição das entidades coletivas à aprovação preliminar do Senado. Nos começos do Império, ou mais precisamente ao tempo de Augusto, a lex Julia de collegiis (57) é votada com esta finalidade, e transforma radicalmente todo o direito corporativo, substituindo o princípio de liberdade de associação pelo de autorização prévia do poder pú-

55) Esta é a Lex Clodia de collegiis, do ano de 55 da era anterior "... "qui ludi sublatis collegiis discussi sunt. Post novem deinde annos, "quam sublata erant, P. Clodius, tribunus plebis, lege lata, restituit "collegia". (Asconius, in SAVIGNY, "Traité", II, p. 251). Igualmente em CICERO: "Iisdem consulibus sedentibus atque inspectatibus, "lata lex est (a Clodio)..." Pro P. Sextio, XV.

56) Há, a respeito, uma passagem de SUETONIO, que exprime exatamente a exceção aberta em favor dos antigos colégios, cuja existência foi respeitada: "Cuncta collegia praeter antiquitus constituta, distraxit." (Julius Caesar, 42).

57) Segundo VON MAYR (op. cit., II, p. 39), a lex Julia de collegiis data do ano 7 desta era, e é pois da época de Augusto, ainda que outras opiniões recuem a sua promulgação ao tempo de Cesar. Não se lhe conhece o texto, depois reconstituido indiretamente, e uma série de mandata e senatusconsulta, que posteriormente a confirmaram e completaram, lançou-a ao esquecimento. A inscrição de Lanuvium, do ano 133 (nota 24, deste cap.), já alude 2.0 regime de permisão prévia, que se havia estabelecido para a formeção dos colégios de assistência mútua, ao transcrever o título do respectivo senatus-consulto: "Kaput ex SC. populi romani: "quibus coire, convenire collegiumque habere liceat." 
blico. Extinguindo todos os colégios existentes, à exceção de alguns, a lei estabeleceu a necessidade da outorga de uma autorização preliminar e espeical para a constituição de uma associação. A permissão devia ser dada pelo Senado, ou pelo Imperador, depois da manifestação do Senado, devendo o colégio preencher certas condições, e, entre estas, a de não apresentar nenhum perigo e ter o caráter de utilidade pública. (58) In summa, repete posteriormente Marciano, nisi ex senatusconsulti auctoritate, vel Caesaris, collegium vel quodcunque tale corpus coierit, contra senatusconsultum, et mandata, et constituciones collegium celebrant, (59) o que, em outros termos, Gaio, reproduz. (60)

Desde que se instituiu o regime imposto pela lex de collegiis, escreve Waltzing, "tôda a corporação passou a ser necessàriamente autorizada, e a autorização, uma vez obtida, lhe dá o caráter de uma instituição de utilidade pública, de um verdadeiro organismo interior do Estado, gozando de certos privilégios, tal o da personificação civil. Desde então os colégios têm um duplo caráter, público e privado." (61)

Para esta última consequência concorre, sem dúvida, a natureza do ato permissivo do Senado, que não importa apenas no levantamento da proibição genérica, oposta à livre associação dos indivíduos. 0 senatus-consulto que, fundado na lex de collegiis, autoriza a constituição de um dêsses grupos associativos, é, ao invés, um verdadeiro ato de creação, e daí decorre que a vida jurídica, e portanto a capacidade, ou, no sentido amplo, a personalidade do colégio nasce de uma verdadeira concessão do Estado. Êste crea um direito novo, em lugar de reconhecer apenas um direito preexistente, e uma tal concessão administrativa não pode deixar de importar numa obra de creação positiva, tendo por fim constituir a associação como instituição

58) WALTZING, op. cit., I p. 119.

59) D. 3 \& $1(47,22)$.

60) GAIO: "Neque societas, neque collegium, neque hujusmodi corpus "passim omnibus habere conceditur: nam et legibus, et senatuscon"sultis, et principalibus constitutionibus ea res coercetur." D. $1(3,4)$.

61) WALTZING, loc. cit. 
estruturada nos moldes dos organismos de direito público, à maneira do Estado ou do município. (62)

Esta conclusão é, de certo modo, referendada pelos textos, em que, a respeito dos colégios, se alude à concessão do direito de reunião, quibusdam collegiis vel corporibus quibus jus coeundi lege permissum est, sendo ainda melhor confirmada pela asserção, feita logo a seguir, de serem os mesmos colégios instituidos em razão da necessidade e utilidade pública do seu trabalho, instituta sunt, ut necessariam operam publicis utilitatibus exhiberent. (63)

Ainda que não seja de emprestar-se importância decisiva à expressão literal dessas passagens, delas entretanto resulta que o conceito de creação, ao menos no sentido legal, ajusta-se, com mais propriedade, que o de simples permissão posterior, ao fato do texto aludir ao direito de reunião e de instituição do colégio como sendo decorrente expressamente da lei.

Nem por isso, entretanto, é menos certo que, na prática, o Senado, à proporção que se vai tornando juiz exclusivo da autorização, tende a afrouxar o rigor inicial, para contentar-se, afinal, com a prova da inocuidade da associação.

No Alto Império, inúmeras corporações se formam sem intervenção expressa do poder público, e o regime de simples tolerância substitue-se ao de autorização expressa, que entra em desuso. Desde que o colégio se formou livremente, a sua própria continuidade pressupõe-no tàcitamente autorizado. (6)

A autorização, imposta pela lei, deve ser, de sua vez, especial para cada colégio, e esta conclusão se impõe em face dos textos legais, que subordinam o agrupamento dos indivíduos em colégios ao regime de prévia autorização. (65) Esta visa,

62) Esta conceituação, levada às mais extremas consequências, vamos encontrá-la também em FERRARA, para quem as coletividades do tempo da República, e ainda do Império, se apresentam invariavelmente com o carater publicístico, sacral ou estatal: "Aos indivíduos se contrapõem as entidades coletivas, não como associações privadas, mas sempre sob a forma de corpos públicos: tôdas as associações se reduzem a institutos do Estado" (op. cit. cap. I, § 1).

63) CALISTRATO, $5 \S 12(50,6)$.

64) SALEILLES, op. cit., III leçon, p. 63.

65) GIRARD, “Droit Romain", p. 243. 
necessàriamente, cada organismo coletivo de per si, e de outro modo não se conciliaria a lei com os intuitos pràticamente objetivados. Abre-se, porém, uma exceção em favor dos collegia tenuiorum, ou seja dos colégios religiosos, a que os jurisconsultos clássicos dão essa denominação, e os romanistas modernos identificam com os collegia funeratitia. (66)

A inscrição de Lanuvium dá a medida exata do regime estabelecido em favor dos collegia dessa ordem. Alí se reproduz o título do senatus-consulto, que indicava quais fôssem aqueles "a quem era lícito formar assembléia, reunir-se e constituir um colégio". O decreto não fôra feito especialmente para os collegiati de Lanuvium: êstes apenas se valiam da autorização genérica, que o senatus-consulto continha, para se organizarem em colégio, e redigirem os seus estatutos, dentro da concessão, dada em globo a tôdas as associações dêsse gênero. Tratava-se, portanto, de uma autorização geral, prèviamente outorgada em Iavor dos collegia tenuiorum.

Um texto de Marciano (67) corrobora essa conclusão. D̉epois de declarar que é vedado aos presidentes das províncias permitirem a constituição de collegia sodalitia, ainda mesmo entre os soldados, acrescenta que é concedido aos mais pobres dêles, aos tenuiores, juntar em comum uma contribuição mensal, para o fim de se reunirem uma vez por mês. Está aí evidentemente expressa uma autorização de caráter geral, que estende aos próprios soldados, em idênticas condições econômicas, a

66) Sabe-se que foi sob a forma de collegia tenuiorum que se reuniram os primeiros fiéis da religião cristã (GASTON MAY, "Elements de Droit Romain", 1927, p. 71). SAVIGNY assinala a analogia dos antigos clubes da República, sodalitates, com a instituição, evidentemente posterior, dos collegia tenuiorum, mas fixa a distinção, que há entre uns e outros (op. cit., p. 251).

67) MARCIANO: “Mandatis principalibus praecipitur praesidibus provin"ciarum, ne patiantur esse collegia sodalitia, neve milites collegia in "castris habeant. Sed permittitur tenuioribus stipem mesntruam con"ferre, dum tamen semel in mense coeant: ne sub pretextu hujusmo"di illicitum collegium coeat; quod non tantum in urbe, sed et in Ita"lia, et in provinciis lucum habere divus quoque Severus rescripsit". D. $1(47,22)$. 
mesma concessão, que beneficiava, em geral, os collegia tenuiorum. (68)

0 estabelecimento do regime de autorização oficial das associações vinha, sem dúvida, reforçar a aproximação das entidades associativas com as instituições do direito público e, acentuando melhor a identidade de umas e outras, completar a transpormação evolutiva, que nesse aspecto fôra iniciada pela sujeição dos municipia às regras do direito privado. Estabelece-se um plano de incidência, em que vêm confundir-se tôdas as corporações, públicas ou privadas, moldadas estas por aquelas, e assemelhadas na estrutura e na atividade. Um novo conceito corporativo devia testemunhar o desenvolvimento dêsse sistema de associações, ao atingirem a perfeição de sua destinação jurídica, e esta concepção, que envolve, de início, o próprio populus romanus, como a mais alta expressão de comunidade organizada, deverá alcançar tôdas as coletividades, em que a nação se fraciona, não apenas as cidades e os municípios, mas também as corporações e as associações modeladas no seu tipo.

Surge assim o conceito da universitas, que caraterizará a unidade orgânica do agrupamento coletivo, como expresão típica da reunião dos indivíduos associados coletivamente. Sob a sugestão da nova idéia, o conceito pluralístico do populus romanus refunde-se na síntese unitária da Respublica, enquanto - Municipium entra a significar a unidade corporativa dos municipes.

A universitas, como locução destinada a difundir-se, carateriza o sentido exato das individualidades corporativas, tanto de direito público, como de direito privado, para designar a unidade patrimonial das comunidades e associações. $\mathrm{O}$ município e a República alcançam uma significação jurídica, que os

68) Si dúvidas o texto pudesse apresentar, no sentido de se entender que ao praeses provinciarum cabe, em cada caso, verificar da conveniência da autorização, para concedê-la em caráter especial, em favor dos soldados mais desvalidos, bastaria a circunstância da lei estabelecer a vigência daquele benefício, não só nas províncias, mas também na Itália, e ainda em Roma, onde não é de cogitar-se da existência da autoridade, a que o texto alude, no início. Trata-se, portanto, de uma autorização geral. 
individualiza em face dos seus membros componentes: a representação de um ou de outro não se confunde com a representação de cada indivíduo, em separado, do grupo comunal. Considerados um e outrc como uma universitas, são equiparados às universitates, em geral: Si municipes, vel aliqua universitas ad agendum det actorem, non erit dicendum quasi a pluribus datum sic haberi: hic enim pro republica vel universitate intervenit, non pro singulis. (69)

A corporação ganha um sentido de unidade ideal, e essa unidade não se altera, nem se desintegra, ainda que mudem ou se substituam os seus membros; e si êstes se reduzem a um único, a universitas, que é a expressão corporativa, subsiste, sem confundir-se com êste último. (70)

É, em suma, como acentua Holder, (71) a teoria da universitas, que se desenvolve, trazendo consigo a idéia de personalidade, pela primeira vez expressa nos textos, e a sua consequente equiparação à pessoa humana, que lhe serve, não de origem, mas de modêlo ou exemplo, no sentido de caraterizar uma posição jurídica, semelhante a que desfruta o homem nas relações jurídicas, como expressão de capacidade. Tôda a associação autorizada, ou lícita, é assemelhada à pessoa física.

Os juristas formulam de vários modos essa idéia. A herança, tal como o município, a decúria e a sociedade, personae vice fungitur. (72) E ainda que o texto seja argüido de interpola-

69) ULPIANO, D. $2(3,4)$.

70) ULPIANO: “In decurionibus vel aliis universitatibus, nihil refert, "utrum omnes iidem maneant, an pars maneat vel omnes immutati "sint. Sed si universitas ad unum redit, magis admittitur posse eum "convenire et conveniri; cum jus omnium in unum reciderit, et stet "nomem universitatis". D. $7 \S 2(3,4)$.

71) SALEILLES, loc. cit.

72) FLORENTINO: "Mortuo reo promittendi, et ante aditam heredita"tem fidejussor accipi potest: quia hereditas persone vice fungitur. "sicuti municipium, et decuria; et societas". D. $22(46,1)$. 
ção, (73) outros traduzem a mesma idéia. Assim, segundo Gaio, civitates enim privatorum loco habentur, (74) da mesma forma que magistratus municipales, quum unum magistratum administrent, etiam unius hominis vicem sustinent. (75) De idêntico modo, o povo, a cúria, o colégio e a corporação reputam-se uma pessoa em oposição à pessoa singular, et ideo sive singularis sit persona, quae metum intulit, vel populus, vel curia, vel collegium, vel corpus, huic edicto locus erit. (76)

Não há nessa associação de idéias entre a corporação e a pessoa senão uma imagem comparativa, mas esta revela, de pronto, o fenômeno jurídico da unidade associativa. Essa unidade é a que o conceito da universitas sintetisa. 0 ser coletivo é reconhecido, expressamente, como pessoa capaz de direitos patrimoniais, e assume uma personalidade unitária, desde que se apresente, pela sua estruturação, como um grupo organizado sob a forma típica de uma unidade patrimonial, a serviço do interêsse associativo. (77) Surge, do novo conceito, a antítese entre a idéia da coletividade unificada e a pluralidade dos indivíduos, que a formam. A universitas, como um ser único e ideal, opõe-se aos singuli, e distingue-se dêles: é um ser diverso da pluralidade dos seus membros.

Os direitos da universitas não são direitos dos seus membros, nem as obrigações daquela representam obrigações dos singuli: Si quid universitati debetur, singulis non debetur; nec quod debet universitas, singuli debent. (78)

73) Segundo PEROZZI (op. cit., p. 127), com fundamento em FERRINI (Pand. p. 96), o texto primitivo teria sido personae defuncti vice fungitur, à semelhança aliás do que ocorre em outros textos relativos à herança, como êste, de FLORENTINO: "Servo hereditário recte le"gatur, licet ea adita non sit, quia hereditas personae defuncti, que "eam reliquit, vice fungitur." D, $116 \S 3(30,1)$, e bem assim êste outro: "Servus alienus post domini mortem recte heres instituitur; non"dum enim adita hereditas personae vicem sustinet, non heredis fu"turi, se defuncti". I. de heredibus instituendis, § $2(2,14)$. A correção, que FERRINI entende dar ao texto, si aceita, deixaria êste entretanto sem sentido, desde que não é possível dizer-se que o município, a decúria e a sociedade personae defuncti vice funguntur.

74) GAIO, D. $16(50,16)$.

75) ULPIANO, D. $25(50,1)$.

76) ULPIANO, D. 9 § $1(4,2)$.

77) SALEILLES, loc. cit.

78) ULPIANO, D. $7 \S 1(3,4)$. 
Na conceituação dos direitos patrimoniais, acentua-se ainda mais incisivamente a excepcional posição jurídica dos corpos associativos, em face dos indivíduos, para realçar a antinomia, em que se defrontam uns e outros. Até então o patrimônio da associação constituia uma propriedade comum, que pertencia aos indivíduos reunidos. Era a arca communis, indivisível enquanto dura a associação, e que constitue o fundo comum dos membros associados, aos quais pertence indivisamente, a todos ut singuli, propriedade coletiva, que deixou de ser individual, mas ainda não se tornou corporativa. Depois que os colégios assumem a posição de unidade associativa, já o patrimônio passa a considerar-se como pertencente à nova entidade; a universitas, que se superpõe ao conjunto de indivíduos, no seu aspecto de simples pluralidade, e se mostra de certa forma distinta dêles.

Marciano precisa o novo conceito, ao declarar que as cousas públicas, quae in civitatibus sunt theatra, et stadia, et similia, et si qua alia sunt communia civitatum, são da universitas, e não dos membros da cidade, considerados individualmente, universitatis sunt, non singulorum. E ampliando a conceituação da universitas, para dar a medida exata da sua capacidade, em face da capacidade dos singuli, declara que o servo público não pertence aos particulares, a cada um de per si, mas à unidade ideal: nec servus communis civitatis singulorum pro parte intelligitur, sed universitatis. (79)

A universitas surge assim como um sujeito de direitos independente da personalidade dos indivíduos, que se agrupam para integrar a corporação.

Daí afirmar Gierke que a personalidade civil, cuja evolução vimos acompanhando desde os primeiros tempos de Roma, se apresenta, na sua construção jurídica, como uma unidade inteiramente distinta da coletividade, que a constitue, sendo neste aspecto, como quer Savigny, um sujeito de direitos distinto dos indivíduos, que o compõem, ou, como corrige Saleilles, um sujeito de direitos compostos dêsses mesmos indivíduos. (80)

79) MARCIANO, D. $6 \S 1(1,8)$.

80) SALEILLES, op. cit., IV leçon. 